\title{
FORCE BUDGET
}

\author{
(Abstract) \\ by \\ I.M. Whillans *** and C.J. van der Veen *
}

(* Byrd Polar Research Center and ** Department of Geology and Mineralogy,

125 South Oval Mall, The Ohio State University, Columbus, OH 43210, U.S.A.)

\begin{abstract}
An expression for force balance is derived for the general case of gradients in longitudinal and lateral normal stresses and lateral shear stress. In order to consider horizontal glacial mechanics in Newton's style of actions and reactions, the full stresses are partitioned into lithostatic and resistive, $R_{i j}$, components. The lithostatic stress is the weight of ice above, and the horizontal gradient in lithostatic force on a vertical column is the familiar driving stress, which accounts for the horizontal effect of body or action forces. The horizontal resistive-stress components describe the reactions to this horizontal action of gravity. Force balance is
\end{abstract}

$\frac{\partial}{\partial x_{i}} \int_{b}^{h} R_{i i} \mathrm{~d} z+\frac{\partial}{\partial x_{j}} \int_{b}^{h} R_{i j} \mathrm{~d} z-\tau_{\mathrm{bi}}+\tau_{\mathrm{di}}=0, i \neq j=1,2$

with horizontal coordinates $x_{1}, x_{2}$ and vertical $z$. The upper and bottom elevations are $h$ and $b$, and $\tau_{\mathrm{di}}$ and $\tau_{\mathrm{bi}}$ are driving stress and basal drag respectively. This describes net reaction due to normal resistance, lateral shear resistance, and basal drag resistance, and finally the action or driving stress. This equation is exact. Resistive stresses are simply linked to deviatoric stresses, and hence to strain-rates, through the flow law.

\section{FORCE BUDGET: APPLICATION TO THREE-DIMENSIONAL FLOW OF BYRD GLACIER, ANTARCTICA}

\author{
(Abstract) \\ by \\ I.M. Whillans $* * *$, Y.H. Chen ${ }^{* * *}$, C.J. van der Veen $*$ and T.J. Hughes $* * * *$ \\ (The Ohio State University, * Byrd Polar Research Center, ** Department of Geology and Mineralogy, \\ and *** Department of Engineering Mechanics, Columbus, OH 43210, U.S.A., \\ **** University of Maine, Institute for Quaternary Studies, \\ 110 Boardman Hall, Orono, ME 04469, U.S.A.)
}

\section{ABSTRACT}

Stresses at the surface and at depth are calculated for a stretch of Byrd Glacier, Antarctica. The calculations are based on photogrammetrically determined velocities and elevations (Brecher 1986) and on radio-echo-determined ice thicknesses. The results take the form of maps of drags from each valley wall, of normal forces laterally and longitudinally, and of basal drag. Special challenges in the calculation are the numerical gridding of velocity (ensuring that unreasonable short-wavelength features do not develop in the calculation) and inference of ice thicknesses where there are no data.

The results show important variations in basal drag. For the floating part, basal drag is near zero, as expected. Within the grounded part, longitudinal components of basal drag are very variable, reaching $300 \mathrm{kPa}$, with a dominant wavelength of $10 \mathrm{~km}$. Generally these drag maxima correlate with maxima in driving stress, and the across-glacier component of basal drag is usually small. An important exception occurs in the center of the grounded part of the glacier, where the flow shows major deviations from the axis of the valley.

Results also show that side drag is roughly constant at $250 \mathrm{kPa}$ along both margins of the glacier, tension from the ice shelf is about $100 \mathrm{kPa}$, and tension in the grounded part cycles between 250 and $150 \mathrm{kPa}$. Calculated deep velocities are too large and this is attributed to deficiencies in the conventional isotropic flow law used.

\section{REFERENCE}

Brecher, H.H. 1986. Surface velocity determination on large polar glaciers by aerial photogrammetry. Ann. Glaciol., 8, 22-26. 